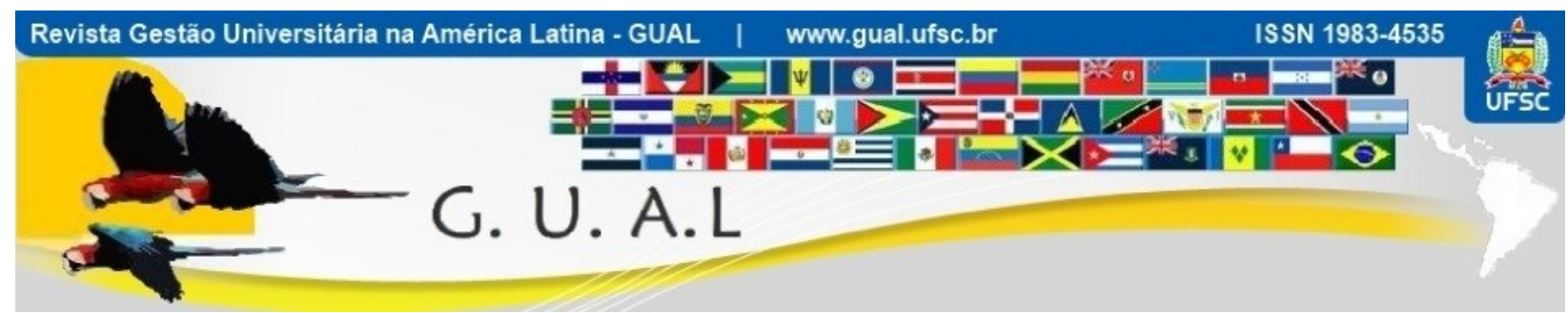

DOI: http://dx.doi.org/10.5007/1983-4535.2018v11n4p231

\title{
APOSENTAR-SE OU CONTINUAR TRABALHANDO? DECISÃO DIFÍCIL PARA SERVIDORES PÚBLICOS
}

\section{RETIRE OR CONTINUE WORKING? DIFFICULT DECISION FOR PUBLIC EMPLOYEES}

Tania Nobre Gonçalves Ferreira Amorim, Doutora

Universidade Federal Rural de Pernambuco - UFRPE tanobre@,gmail.com

Diane Glayce dos Santos Carvalho, Mestranda Universidade Federal de Pernambuco - UFRPE diane.glayce@gmail.com

Rezilda Rodrigues Oliveira, Doutora Universidade Federal de Pernambuco - UFRPE rezilda.rodrigues@gmail.com

Ladjane de Barros Silva, Mestre Universidade de Pernambuco - UPE ladbarros@yahoo.com

Recebido em 24/novembro/2017

Aprovado em 06/setembro/2018

Sistema de Avaliação: Double Blind Review

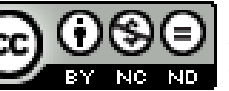

Esta obra está sob uma Licença Creative Commons Atribuição-Uso. 


\title{
RESUMO
}

A Gestão de Pessoas ou Gestão de Recursos Humanos é parte integrante da gestão organizacional com significativa importância em segmentos públicos e privados. Este artigo foi baseado em um trabalho de pós-graduação que estudou a utilização do Abono de Permanência pelos servidores técnicos-administrativos e docentes em uma universidade federal brasileira. O Abono de Permanência pode ser solicitado por servidores que já tenham as condições legais para se aposentarem, mas que por vontade própria decidiram permanecer trabalhando e passam a receber restituição da contribuição social descontada mensalmente. A aposentadoria nem sempre é bem-vinda para muitos profissionais por razões como medo da solidão, perda de status profissional, perdas financeiras e exigência de um novo rumo na vida pessoal. Foi constatado no estudo de caso realizado em uma das maiores universidades federais brasileiras que $15 \%$ do total de servidores ativos estão recebendo esse Abono. Grande parte destes servidores se sente satisfeita com as atividades que desempenha, com o ambiente organizacional, recebe reconhecimento no trabalho e deseja continuar se capacitando, mesmo já tendo condições de se aposentar e pretende permanecer na ativa por mais anos, talvez até a aposentadoria compulsória, que só ocorre aos 75 anos.

Palavras-chave: Servidor Público. Gestão de Pessoas. Abono de Permanência. Aposentadoria.

\begin{abstract}
People Management or Human Resource Management is part of organizational management with significant importance in public and private organizations. This paper was based on a postgraduate study that analyzed the use of the Permanency Allowance by technicaladministrative public employees and professors at a Brazilian federal university. The Permanency Allowance can be requested by employees who already have the legal conditions to retire, but who voluntarily decided to remain working and receive a refund of the social contribution discounted monthly. Retirement is not always welcome for many professionals for reasons such as fear of loneliness, loss of professional status, financial loss, and a new direction in personal life. It was verified in the case study carried out in one of the largest Brazilian federal universities that $15 \%$ of the total active employees are receiving this permanence allowance. Many of these employees feel satisfied with the activities they perform, with the organizational environment, receive recognition at work and wish to continue training themselves, even though they are already able to retire and intend to remain in active employment for more years, perhaps even compulsory retirement, which only occurs at 75 years.
\end{abstract}

Keywords: Public Employee. Human Resources. Permanency Alowance. Retirement. 


\section{INTRODUÇÃO}

A Gestão de Pessoas ou Gestão de Recursos Humanos (RH), na atualidade, é parte integrante da gestão organizacional que tem adquirido significativa importância nos mais variados ramos de atividades, segmentos públicos e privados. Sua importância independe do porte das organizações, mas passa a adquirir maior complexidade à medida em que a organização cresce. Sena e Guarnieri (2015, p. 226) defendem que "a construção e o desenvolvimento de qualquer organização dependem do trabalho das pessoas". Palácios (2014) também defende que as pessoas influenciam e constroem decisivamente o processo estratégico e realidades organizacionais, a partir de suas ações.

Contudo, Tanure, Evans e Cançado (2010), alertam que o discurso de sua importância, praticado pelos profissionais de $\mathrm{RH}$, muitas vezes não é efetivado no cotidiano da gestão organizacional. E isto também ocorre no setor público brasileiro, em que a gestão de RH sofre de descontinuidades e pouca estruturação dos seus subsistemas (CARVALHO et al., 2009; PIRES et al., 2005).

Assim, a gestão de pessoas é um subsistema organizacional que se utiliza de várias ferramentas essenciais ao seu desempenho, com desafio central de ser estratégica, para atrair e manter profissionais eficientes, através de políticas e ações de recrutamento e seleção de pessoal, treinamento e desenvolvimento, remuneração, reconhecimento dos funcionários, e qualidade de vida no trabalho (NGUYEN; NGUYEN, 2011; CLERKIN; COGGBURN, 2012).

Ferreira et al. (2015, p.185) defendem que ações de treinamento e desenvolvimento dos funcionários são importantes para a sustentabilidade organizacional. Por isto, as organizações investem e aperfeiçoam seus profissionais. "Importante ressaltar que as mudanças na forma de gerir pessoas e a percepção da importância em se ter pessoas mais capacitadas nas organizações têm ocorrido não apenas nas empresas privadas, mas também na Administração Pública".

Barbosa e Ferreira (2009) e Magalhães et al. (2010) relatam que a adequação dos RH é tarefa prioritária no desenvolvimento de pessoal, porque possibilita mais competências e melhor desempenho na prestação de serviços aos cidadãos. Appelbaum et al. (2000, p.50) ressaltam esse pensamento ao afirmarem que "[...] as pessoas têm melhor desempenho (performance) quando têm habilidade em forma de conhecimento e capacitação para desenvolver o trabalho". 
O histórico ds mudanças da área de Recursos Humanos e Gestão de Pessoas no Brasil mostra que foram inicialmente protagonizadas pelas multinacionais que trouxeram sua experiência com a inserção de novos princípios de divisão do trabalho e meritocracia, associados às práticas gerais de recrutamento, seleção, treinamento e desenvolvimento dos funcionários. Contudo, as mudanças decorrentes das novas realidades sociais, políticas e econômicas provocaram alterações nas relações entre as organizações, trabalhadores e suas carreiras, porém, com mais efetividade nas organizações privadas do que nas organizações públicas, no Brasil (WOOD JR, TONELLI e COOKE, 2011; DAVEL; VERGARA, 2013; SILVA, J. R; BALASSIANO; SILVA, A. R. L, 2014). Salles e Nogueira (2013) salientam que apesar de todas essas transformações ocorridas no serviço público federal brasileiro os modelos adotados na área de Gestão de Pessoas continuam tradicionais, inflexíveis e complexos.

Moura e Souza (2016), Nascimento e Simões (2011) e Ferraz e Rocha (2011) defendem que estudos em organizações públicas mostram ênfase em atividades operacionais pelos gestores de RH, associadas ao fato de que os servidores não conseguem perceber efetivamente grande parte das ações e iniciativas da área. Moura, Dias e Silva Júnior (2013) constataram em seus estudos que há burocracia rígida na área, gestão antiquada e com ênfase operacional que permite pouco espaço para reflexão e uma gestão proativa e estratégica de recursos humanos em organizações públicas.

Este artigo foi baseado em um trabalho de pós-graduação que estudou a utilização do Abono de Permanência pelos servidores técnicos-administrativos e docentes, em uma universidade federal brasileira. O Abono de Permanência corresponde à devolução da contribuição previdenciária que o servidor recolhe mensalmente, em tono de $11 \%$, ao servidor que completou todas as exigências para solicitar sua aposentadoria voluntária, mas que opta por permanecer em trabalhando. A base legal do Abono de Permanência é a Emenda Constitucional $n^{\circ} 41 / 2003$ em seu artigo $2^{\circ}, \S 5^{\circ}$.

O estudo buscou realizar um diagnóstico do quadro de servidores aposentáveis da universidade federal estudada, ou seja, daqueles servidores que já tinham as condições legais para se aposentarem, mas que por vontade própria decidiram permanecer trabalhando, tendo solicitado o benefício financeiro do Abono de Permanência a que fazem jus. A pergunta de pesquisa foi: Quais motivos levam os servidores da universidade a requererem o Abono de Permanência? 
Para atender ao objetivo proposto, o estudo identificou quais servidores possuem os requisitos necessários para a aposentadoria na universidade, traçou o perfil dos servidores que já estão usufruindo do Abono de Permanência no ano de 2016 e analisou as causas que eles declararam com razão para continuar na ativa.

\section{FUNDAMENTAÇÃO TEÓRICA}

\subsection{A GESTÃO DE PESSOAS COM ÊNFASE EM ORGANIZAÇÕES PÚBLICAS}

A evolução dos estudos de Gestão de Pessoas e Gestão de Recursos Humanos no Brasil mostrou que a área busca alinhar suas políticas à realidade do contexto sócio-político nacional, visando incluir o país nesse ambiente competitivo, segundo estudos de Wood Jr., Tonelli e Cooke (2011). Os autores analisaram o período de 1980 a 2010, confirmando que as pessoas são o principal desafio estratégico da área. Bohlander e Snell (2009) comungam com essa perspectiva e defendem que a gestão de RH busca primordialmente gerenciar talentos para atingir os objetivos organizacionais.

A Gestão de Pessoas na atualidade entende o funcionário como estratégico, uma vez que que ele passa a ser a peça chave para o alcance de efetividade e competitividade organizacional. Suas políticas e práticas estão diretamente relacionadas aos valores e estratégias organizacionais (HORTA; DEMO; ROURE, 2012; ARMSTRONG, 2012; MORRIS; SNELL, 2010). Demo, Fernandes e Fogaça (2017, p. 100), por sua vez, entendem que "há um consenso de que as práticas de GP produzem desempenho organizacional superior quando são utilizadas em conjunto e de maneira integrada à estratégia de negócios”.

Oliveira et al. (2017, p.110) citam Silveira e Miranda (2011) ao salientarem que a Gestão de Pessoas deve abranger grandes decisões organizacionais, além da implantação e adaptação das pessoas e os processos que as envolvem, devendo "gerar e sustentar recursos estratégicos, desenvolver capacidades e competências organizacionais e criar organizações mais flexíveis e inteligentes do que os seus competidores, por apresentarem níveis superiores de cooperação, coordenação e inovação".

A área de Gestão de Pessoas em organizações públicas, na visão de Jackson Filho e Ponce (2017), está sujeita a uma gama de peculiaridades específicas do serviço público. O desafio de implantar ações efetivas e atualizadas é muito grande, pela elevada burocracia trabalhista e especificidades das organizações públicas. Já Carvalho et al. (2009) e Pires et al. (2005) reafirmam que a gestão pública de recursos humanos sofre descontinuidades e 
dificuldades na estruturação dos seus sistemas, além de nem sempre ser tema da agenda de governo.

Já Moura e Souza (2016, p.582) citam o estudo que Marconi (2010) realizou elaborando um diagnóstico sobre a gestão de pessoas no Governo Federal, de 1995 a 2009 e constatou distorções que impedem uma política de RH efetiva, com a ausência de "planejamento da força de trabalho que dimensione o contingente e o perfil necessários e a ausência de uma estrutura de incentivos que estimule o desenvolvimento profissional". Nascimento e Simões (2011) também afirmam que no serviço público ainda há muita ênfase nas atividades operacionais dentre as realizadas pelos gestores de $\mathrm{RH}$.

\subsection{REMUNERAÇÃO: SALÁRIO, INCENTIVOS E BENEFÍCIOS}

Com as mudanças advindas do cenário econômico e social dos últimos anos, as políticas de remuneração de pessoal foram sendo atualizadas, ampliando a concepção de uma remuneração mais flexível, além do tripé tradicional de salário, incentivos e benefícios. É dada maior ênfase em incentivos do que no próprio salário ou remuneração básica, pois os incentivos estão relacionados à produtividade e recompensam o desempenho, de modo a contribuir com os resultados organizacionais (TACHIZAWA et al., 2004; MILKOVICH; BOUDREAU, 2010).

$\mathrm{Na}$ literatura, há diferentes colocações que tratam deste assunto. Por exemplo, os benefícios constituem a parte indireta da remuneração, vantagens contempladas pelos funcionários e organização, mas causam impactos financeiros nas despesas da empresa. Influenciam na satisfação e ajudam na construção de um ambiente de segurança psicológica, social e econômica. Adicionalmente, buscam proporcionar uma melhor qualidade de vida, favorecer um ambiente de trabalho equilibrado, produtivo e com competitividade organizacional, além de ser fator de atração e retenção organizacional. Podem ser obrigatórios ou exigidos por lei, como décimo terceiro salário, salário família e férias. E espontâneos ou opcionais, dependendo das estratégias das organizações buscando melhoria de qualidade de vida dos funcionários, como seguro de vida, assistência médica, plano de complementação para aposentadoria (OLIVEIRA; LEONE, 2008; ARAUJO; GARCIA, 2009; MARRAS, 2009; BOHLANDER; SNELL, 2010; MILKOVICH; BOUDREAU, 2010; STEFANO; CAMPOS; CHRIST, 2014). 


\section{APOSENTAR-SE OU CONTINUAR TRABALHANDO? DECISÃO DIFÍCIL PARA SERVIDORES

Por seu turno, a remuneração dos servidores públicos federais no Brasil é baseada no Regime Jurídico Único dos Servidores Públicos Civis Federais, conforme estabelece a lei $n^{\circ}$ 8.112/1990 (BRASIL, 1990). Inclui inúmeros benefícios obrigatórios e dentre eles está o Abono de Permanência, tema deste estudo. O mesmo foi instituído na Emenda Constitucional (EC) $n^{\circ} 41 / 2003$ (BRASIL, 2003) e se caracteriza como uma indenização pecuniária concedida aos servidores em cargo efetivo, com os requisitos necessários para se aposentarem atendidos, que de modo voluntário, optam por continuar trabalhando, podendo ser mantido até a aposentadoria compulsória, atualmente aos 75 anos. O valor do abono é equivalente ao da sua contribuição previdenciária, o Plano de Seguridade Social - PSS (ELIAS, 2009), atualmente em 11\%. A concessão do Abono de Permanecia visa incentivar o servidor a continuar trabalhando e gerar uma economia ao governo, porque o servidor aposentado continuará na folha de pagamento e outro servidor o substituirá (SERTÃO, 2005).

Quadro 1 Regras e requisitos para a aposentadoria Federal

\begin{tabular}{|c|c|}
\hline Regras & Requisitos \\
\hline $\begin{array}{l}\text { Artigo } 40 \text { da Constituição Federal /1988, com } \\
\text { redação dada pela EC nº 41/2003 (Regra geral) - } \\
\text { (BRASIL, 1988) }\end{array}$ & $\begin{array}{l}\text { - Mulher: } 55 \text { anos de idade e } 30 \text { anos de contribuição } \\
\text { - Homem: } 60 \text { anos de idade e } 35 \text { anos de contribuição } \\
\text { - } 10 \text { anos de efetivo exercício no serviço público } \\
\text { - } 05 \text { anos no cargo em que se der a aposentadoria }\end{array}$ \\
\hline $\begin{array}{l}\text { Artigo } 2^{\circ} \text { da } \mathrm{EC} \mathrm{n}^{\circ} 41 / 2003 \\
\text { (Regra de transição) (BRASIL, 2003) }\end{array}$ & $\begin{array}{l}\text { - Ingresso no serviço público até } 16 / 12 / 1998 \\
\text { - Mulher: } 48 \text { anos de idade e } 30 \text { anos de contribuição } \\
\text { - Homem: } 53 \text { anos de idade e } 35 \text { anos de contribuição } \\
\text { - } 05 \text { anos no cargo em que se der a aposentadoria } \\
\text { - Pedágio }(20 \%) \text { e redutor }(3,5 \% \text { ou de } 5 \%)\end{array}$ \\
\hline $\begin{array}{l}\text { Artigo } 6^{\circ} \text { da } \mathrm{EC} n^{\circ} 41 / 2003 \\
\text { (Regra de transição) (BRASIL, 2003) }\end{array}$ & $\begin{array}{l}\text { - Ingresso no serviço público até } 31 / 12 / 2003 \\
\text { - Mulher: } 55 \text { anos de idade e } 30 \text { anos de contribuição } \\
\text { - Homem: } 60 \text { anos de idade e } 35 \text { anos de contribuição } \\
\text { - } 20 \text { anos de efetivo exercício no serviço público } \\
\text { - } 10 \text { anos na carreira em que se der a aposentadoria } \\
\text { - } 05 \text { anos no cargo em que se der a aposentadoria }\end{array}$ \\
\hline $\begin{array}{l}\text { Artigo } 3^{\circ} \text { da EC n }{ }^{\circ} 47 / 2005 \\
\text { (Regra de transição) (BRASIL, 2005) }\end{array}$ & $\begin{array}{l}\text { - Ingresso no serviço público até 16/12/1998 } \\
\text { - Mulher: } 55 \text { anos de idade e } 30 \text { anos de contribuição } \\
\text { - Homem: } 60 \text { anos de idade e } 35 \text { anos de contribuição } \\
\text { - } 25 \text { anos de efetivo exercício no serviço público } \\
\text { - } 15 \text { anos na carreira em que se der a aposentadoria } \\
\text { - } 05 \text { anos no cargo em que se der a aposentadoria } \\
\text { - Redutor de idade, para cada ano que exceder os } \\
\text { 30/35 de contribuição, diminui um ano da idade } \\
\text { 55/60. }\end{array}$ \\
\hline
\end{tabular}

Fonte: Dados do levantamento bibliográfico

Para receber o referido Abono é necessário que o servidor faça a solicitação para permanecer trabalhando e cumpra os requisitos para a aposentadoria. Estando tudo correto na solicitação é feita a implantação do Abono de Permanência no SIAPE - Sistema Integrado de 
Administração de Recursos Humanos Federal e encaminhado para o setor financeiro para implantação do pagamento do benefício ao servidor solicitante.

\subsection{O TRABALHO E SUA IMPORTÂNCIA NA VIDA DAS PESSOAS}

O trabalho dá sentido à vida. Atende a necessidades básicas, de autoestima e realização pessoal (ZANELLI; SILVA; SOARES, 2010). Seu entendimento sofreu inúmeras interpretações, com o passar dos tempos. Segundo Moreira (2011, p. 543), "o trabalho humano parte do extremo da desvalorização, da atividade considerada como inferior portanto, obrigação dos subalternos -, no contexto da pré-modernidade”. Para ele, atualmente o trabalho tem grande valor, define identidade e tem lugar privilegiado na vida das pessoas, garantindo sua sobrevivência.

O trabalho pode gerar muitas emoções nos indivíduos, desde grande prazer e realização a frustrações e adoecimento. Insere o profissional em realidades diversas, nem sempre atendendo aos princípios de uma boa convivência humana, sendo muito mais do que o grande supridor de renda ao trabalhador, uma vez que grande parte de sua vida adulta e relações interpessoais são advindas das experiências profissionais (DEJOURS, 2008; STEGER; DIK; DUFFY, 2012; KUBO; GOUVÊA; MANTOVANI, 2013; SOUZA et al. 2013; VILELA; GARCIA; VIEIRA, 2013). Boas e Morin (2016) lembram que o trabalho pode desenvolver o potencial dos indivíduos, proporciona autonomia, facilita o processo de tomada de decisões e solução de problemas e protagoniza a evolução na carreira.

Em termos da atividade acadêmica desempenhada pelo docente, há particularidades. Segundo Machado e Lucas (2017, p.580) "O trabalho docente exige domínio cognitivo, instrumental, socialização e vivência profissional para que a construção da identidade profissional ocorra". Tardif e Raymond (2000, p. 239) comentam que o trabalho docente envolve "elementos emocionais, relacionais e simbólicos que permitem que um indivíduo se considere e viva como um professor e assume, assim, subjetivamente e objetivamente, o fato de fazer carreira no magistério".

Carmo (2001, p. 15) entende que o trabalho utiliza a inteligência e consegue modificar o homem. Para ele, "Realizando essa atividade, o homem se transforma, se autoproduz e, ao se relacionar com outros homens, estabelece a base para as relações sociais. Antunes (2014, p. 30) defende que "é pertinente observar que a carga horária excessiva de trabalho é considerada como prejudicial ao indivíduo, tanto pelas consequências que ocasiona em sua 
saúde quanto pela restrição de envolvimento pessoal em outros contextos". Nos estudos de Machado e Lucas (2017, p.585) eles chegaram à conclusão que os professores sentem sobrecarga pela rotina escolar que "os limitava no exercício de seus papéis fora da escola, pois sempre estavam ocupados com atividades profissionais, deixando de lado seus gostos, suas famílias e seu lazer, privando-se de sua liberdade".

Conforme apresentado, o trabalho é importante elemento na vida adulta das pessoas. Contudo, há significativas diferenças entre o trabalhador da iniciativa privada e o servidor público, uma vez que para se tornar servidor público no Brasil é exigido fazer concurso. Ser servidor é visto como uma grande conquista, resultado de muito estudo e esforço, tendo como prêmio um emprego estável (LIMA; SILVA, 2014).

\subsection{UNIVERSIDADES E SUAS PECULIARIDADES}

As universidades são organizações complexas e uma das mais antigas no mundo. Têm papel fundamental no desempenho econômico e social de um país, com objetivo de gerar e transmitir conhecimentos, formar cidadãos e apoiar o desenvolvimento da sociedade, podendo ser pública ou privada, cumprindo o tripé de ensino, pesquisa e extensão universitária. (CHEN; YANG; SHIAU, 2006; SURYADI, 2007; UMASHANKAR; DUTTA, 2007; LIMA et al., 2009; MAGALHÃES et al., 2010; MITCHELL; RYDER, 2013; PAIVA et al., 2014; ASIF; SEARCY, 2014; PALÁCIOS, 2014).

$\mathrm{Na}$ atualidade, as universidades têm grandes desafios gerenciais e funcionais, pois no Brasil houve uma abertura proporcionada pela maior flexibilidade para a instalação de faculdades e universidades no País. Isto vem ocorrendo, em especial, com as universidades públicas brasileiras, sem falar que os recursos estão se tornando cada vez mais escassos e há concorrência acirrada tanto em termos discentes, como docentes e funcionais. Assim, a gestão pública universitária precisa ser repensada, em termos de maior eficiência, eficácia e efetividade, para serem mais competitivas em longo prazo (LIMA et al., 2009; PIRES; ROSA; SILVA, 2010; MAGALHÃES et al., 2010; PINGLE; NATASHAA, 2011; MEYER JUNIOR; PASCUCCI; MANGOLIN, 2012; PAIVA et al., 2014; ASIF; SEARCY, 2014; HLADCHANKO, 2015).

Alguns autores, tais como Marra e Melo (2005), Mainardes, Miranda e Correia (2011) e Sanseverino e Gomes (2017), afirmam que a gestão universitária no Brasil não é bem planejada, sofre influência de fatores políticos, extensa burocracia, conflitos de interesses e 
jogos de poder entre suas unidades que torna sua gestão pouco eficiente, lenta e com excesso burocrático em seus processos administrativos, gerenciais e acadêmicos.

No estudo desenvolvido por Moura e Souza (2016, p.587) mapeou 43 instituições públicas federais da administração indireta, com a seguinte distribuição: Autarquias (42\%), Fundações Públicas (37\%) e Autarquias Especiais (21\%), 58\% vinculadas à área de Educação. Em todas elas foi constatado que há discrepância entre o discurso e a prática da gestão de RH. "Os resultados indicam que a inserção estratégica da área de RH nas estruturas e nos processos decisórios das instituições públicas ainda é uma questão a ser conquistada".

Não é por acaso que Gomes e Alves (2015, p.252) afirmam que "O desenvolvimento do servidor público na carreira é fruto do investimento do governo para que possa proporcionar maior e melhor retorno a população sob a forma de prestação de serviços à sociedade". Sanseverino e Gomes (2017, p.477) salientam que “A universidade perde um profissional qualificado ao subutilizá-lo em outra função não compatível com a complexidade exigida para o cargo."

Frente a todos esses desafios as universidades são requisitadas a se reinventarem e seguirem novas regras de gestão. Associado a isto, são exigidas para terem maior produtividade, sendo avaliadas por diversas formas e exigindo maior flexibilidade. Isto tudo influencia o trabalho do servidor, em especial do professor universitário (VILELA; GARCIA; VIEIRA, 2013). Até mesmo a Gestão de Pessoas nas universidades sofre das mesmas mazelas das demais instituições públicas, das quais se exige obedecer aos mesmos processos burocráticos e legais da esfera federal.

\subsection{O ENVELHECIMENTO E A APOSENTADORIA}

Associado a tudo isso, a população idosa no Brasil tem aumentado expressivamente nos últimos anos. O envelhecimento é inevitável e se caracteriza por mudanças físicas, comportamentais, relacionais e psicológicas, que podem trazer crises existenciais diversas ao profissional, pois a aposentadoria geralmente traz consigo perdas financeiras e sociais diversas. A forma de encarar a aposentadoria é influenciada pela vida, relações familiares e sociais, além da forma como o indivíduo encara perdas e mudanças, afetando suas relações e convivência com familiares e amigos, a partir de então. Assim, a preparação para a aposentadoria é fundamental para qualquer trabalhador e muitos são resistentes a ela (NÉRI, 2004; SPIRDUSO, 2005; SOARES, et al., 2007; DEBETIR, 2011;CAMBOIM, et al., 2011). 
Souza et al. (2013, p.112) salientam que "o processo de envelhecer é um fenômeno biológico, construção sociocultural, vinculado a expectativas, valores e ética predominantes. Atingir a maturidade/velhice significa perda de status e prestígio, com a diminuição da capacidade produtiva". Segundo o IBGE (2012), no censo demográfico de 2010, brasileiros com 60 anos ou mais correspondem a $11,6 \%$ da população, ou 20,59 milhões de brasileiros. Destes, em torno de $20 \%$ dos aposentados ainda trabalham e pretendem continuar por mais tempo trabalhando (IBGE, 2012).

É interessante assinalar que "a aposentadoria é um período de reestruturação da atividade e valores" (ROMANINI; XAVIER; KOVALESKI, 2005, p. 379). Rodrigues (2000, p. 28) explica que, em relação à aposentadoria "alguns a vivem como um tempo de "liberdade", de "desengajamento profissional", de "possibilidade de realizações", de "fazer aquilo que não teve tempo de fazer" durante a vida ativa, de "aproveitar a vida", de "não ter mais patrão, horários obrigatórios" etc., [...]”. mas outros têm visão oposta e frustrante sobre a aposentadoria.

Costa (2009, p. 34) ressalta que a aposentadoria não deve "ser vista como o fim dos projetos, mas sim, como um recomeço”. Antunes; Soares; Moré (2015, p. 438) assinalam que na aposentadoria o "contexto familiar ocupa um lugar central na vida do aposentado e é uma das suas principais referências e espaços de pertencimento neste período”. Já Fernandes, Marra e Lara (2016), Wang, Henkens e Solinge (2011) e Marra et al. (2015) constataram em seus estudos a emergência de sentimentos contraditórios em relação à aposentadoria como medo do tédio, da solidão, da instabilidade financeira e de doenças, os quais levam ao seu adiamento.

\section{METODOLOGIA}

A pesquisa que deu origem a este artigo foi um estudo de caso, realizado em uma universidade federal brasileira. Segundo Gressler (2004) os estudos de caso são específicos de uma unidade, mas buscam abranger diferentes pontos de vista da situação. A pesquisa buscou identificar e analisar os motivos que levam os servidores de uma universidade federal brasileira a permanecerem trabalhando, após completarem os requisitos para a aposentadoria.

A universidade federal estudada é considerada uma das melhores universidades do Brasil, conforme avaliação do Ministério da Educação (MEC) e do Ministério de Ciência, Tecnologia e Inovação (MCTI). Alguns dados acerca desta instituição, cuja fonte e 
identificação está sendo resguardada, apontam que esta funciona há mais de 60 anos e agrupa mais de 43 mil alunos e mais de 7 mil servidores docentes e servidores técnicoadministrativos. A universidade estudada possui três campi, sendo a sede na capital e os demais no interior do estado. Possui 10 centros acadêmicos, biblioteca central e dez bibliotecas setoriais e oito órgãos suplementares. Em 2016 a referida universidade ofereceu 100 cursos de graduação, 56 cursos de pós-graduação lato sensu (especializações) e 133 cursos de pós-graduação stricto sensu, sendo 71 Mestrados Acadêmicos, 11 Mestrados Profissionais e 51 Doutorados. Neste mesmo ano, 1.053 servidores estavam recebendo o Abono de Permanência, de um total de pouco mais de 7.000 servidores, sendo $79 \%$ servidores técnicos-administrativos e os demais docentes.

Quanto ao método de pesquisa, seguiu-se a orientação de Creswell (2009) pois foram utilizadas técnicas quantitativas e qualitativas, a fim de atingir um melhor entendimento do problema de pesquisa. Para a realização do estudo definiu-se a amostra estratificada e por conveniência de $10 \%$ dos servidores que recebem o citado Abono de Permanência. Apesar de ser uma amostra por conveniência, buscou-se convidar para participar da pesquisa servidores que estivessem vinculados a todas as unidades acadêmicas e órgãos suplementares dessa instituição, a fim de obter dados mais amplos que aglutinassem opiniões das várias áreas da universidade, uma vez que há diferenças significativas entre elas, devido à natureza das atividades realizadas, condições de trabalho, gestão e serviços envolvidos.

A coleta de dados foi feita entre maio e junho de 2016, a partir de um questionário, elaborado para o estudo, com questões abertas e fechadas, no qual se buscou traçar o perfil dos servidores que solicitaram o Abono de Permanência e os motivos que os levaram a essa escolha. A segunda parte do questionário se referiu ao ambiente de trabalho, para que se conhecesse a percepção do servidor quanto à estrutura física, equipamentos, comprometimento da equipe, nível de stress, satisfação e reconhecimento no trabalho e a contribuição das atividades desenvolvidas para sua carreira, além do tempo que pretende se manter trabalhando, sem solicitar sua aposentadoria.

Para a análise dos resultados obtidos foi utilizada a estatística descritiva básica, aplicada às perguntas fechadas, enquanto que nas perguntas abertas foi usada a análise de conteúdo, seguindo o que Vergara (2005) defende ao dizer que esta é uma técnica para apuração de dados que identifica o que está sendo alegado sobre determinado tema e ainda admite o uso de abordagens mistas. 


\section{RESULTADOS}

O presente estudo analisou as respostas de 105 servidores, distribuídos nas diversas unidades acadêmicas da universidade. Em relação ao perfil do servidor que está usufruindo do Abono, foi identificado que a maioria dos respondentes era do gênero feminino (77\%). Quanto à posição na estrutura de pessoal da universidade, a maioria dos servidores é ocupante do cargo de servidor técnico-administrativo (79,05\%), sendo um percentual bem mais elevado do que a proporção de todos os servidores da universidade, em que os técnicosadministrativos correspondem a 59\% do total de servidores da instituição.

Em relação à faixa etária dos servidores que estão no Abono de Permanência, verificou-se que a maioria está acima dos 56 anos, mas cerca de $20 \%$ deles têm até 55 anos. Mesmo assim, apenas 23,81\% dos servidores que estão no abono têm entre 61 e 65 anos, e efetivamente os mais idosos não chegam aos $10 \%$. A distribuição da faixa etária ora apresentada se encontra na Tabela 1. Assim, podem ser considerados como profissionais que estão na maturidade de suas carreiras, mas ainda podem trabalhar por muitos anos, antes de decidirem efetivamente pela aposentadoria, que para muitos, é um período que traz perdas pessoais, financeiras e profissionais com muitas resistências a ela, como defendem muitos autores, a exemplo de Soares et al. (2007), Debeti (2011) e Camboim et al. (2011).

Tabela 1 Faixa etária dos servidores

\begin{tabular}{ccc}
\hline Faixa etária & Quantidade & $\mathbf{\%}$ \\
\hline Até 40 anos & 0 & 0,00 \\
De 41 a 50 & 1 & 0,95 \\
De 51 a 55 & 20 & 19,05 \\
De 56 a 60 & 50 & 47,62 \\
De 61 a 65 & 25 & 23,81 \\
De 66 a 70 & 9 & 8,57 \\
\hline Total & 105 & 100 \\
\hline
\end{tabular}

Fonte: dados da pesquisa

Quanto ao nível de escolaridade dos servidores pesquisados, é interessante constatar que a grande maioria é pós-graduado (Tabela 2). Percebe-se, então que o nível de escolaridade desses servidores é bastante elevado e que sua aposentadoria deles causará uma perda considerável no capital intelectual da universidade pesquisada, sobretudo daqueles servidores mais qualificados. Vale alertar que Gomes e Alves (2015) lembram que o desenvolvimento do servidor público é fruto de altos investimentos, ao mesmo tempo que 
Sanseverino e Gomes (2017) que salientam a perda de servidores quando eles são subutilizados em suas funções.

Tabela 2 Nível de Escolaridade

\begin{tabular}{ccc}
\hline Escolaridade & Quantidade & $\mathbf{\%}$ \\
\hline Pós-graduação & 87 & 82,86 \\
Médio completo & 8 & 7,62 \\
Graduação & 6 & 5,71 \\
Médio incompleto & 2 & 1,90 \\
Fundamental & 1 & 0,95 \\
Incompleto & 1 & 0,95 \\
Fundamental Completo & 105 & 100 \\
\hline Total & 105
\end{tabular}

Fonte: dados da pesquisa

A análise dos dados quanto as faixas salariais dos servidores que estão recebendo o Abono de Permanência mostrou que a maioria recebe acima de $\mathrm{R} \$ 5.510,00$ (71\%), ou seja, basicamente recebem o teto da previdência pelo INSS no Brasil que é pouco mais de $\mathrm{R} \$ 5.000,00$, em 2016. Salienta-se que cerca de um terço da amostra pesquisada recebe remuneração acima dos $\mathrm{R} \$ 8.500,00$ (Tabela 3).

Tabela 3 Faixa salarial dos servidores que recebem Abono de Permanência

\begin{tabular}{lcc}
\hline Faixa Salarial (R\$) & Quantidade & $\mathbf{\%}$ \\
\hline De 1.000 a 2.500 & 0 & 0,00 \\
De 2.510 a 4.000 & 9 & 8,57 \\
De 4.010 a 5.500 & 25 & 23,81 \\
De 5.510 a 7.000 & 27 & 25,71 \\
De 7.010 a 8.500 & 17 & 16,19 \\
Acima de 8.500 & 27 & 25,71 \\
\hline Total & 105 & 100 \\
\hline
\end{tabular}

Fonte: dados da pesquisa

Quanto aos motivos para solicitar o abono de permanência e não a aposentadoria, as respostas individuais foram aglutinadas em 7 (sete) categorias listadas na Tabela 4. Os resultados revelam sentimentos positivos perante a universidade e ao trabalho que realizam, além da questão financeira, uma vez que com o recebimento do Abono têm o equivalente a um aumento de $11 \%$ nos seus vencimentos. Nota-se que também que foi citado o motivo de querer usufruir o direito legal de receber o abono pelo tempo que desejar, ou até a aposentadoria compulsória, que só ocorre aos 75 anos. 
Assim, observa-se que $91 \%$ dos servidores beneficiados pelo Abono têm idade a partir dos 51 anos. Então, eles têm muito tempo para permanecerem trabalhando. Inclusive, a faixa etária mais elevada que vai dos 66 a 70 anos, corresponde a apenas 8,57\% dos servidores (Tabela 4)

Tabela 4 Motivos informados pelos servidores para solicitarem o abono de permanência

\begin{tabular}{llc}
\hline \multicolumn{1}{c}{ Motivos informados pelos servidores } & Percentual \\
\hline A & $\begin{array}{l}\text { Não querem ou não têm interesse em se aposentar, pretendem ficar por mais um } \\
\text { tempo na universidade. }\end{array}$ & $12 \%$ \\
B Sendo um direito do servidor, querem usufruir disso. & $8 \%$ \\
C $\quad \begin{array}{l}\text { Aguardando concluir alguma progressão na carreira, completar um curso ou } \\
\text { completar os requisitos para se aposentar por uma regra mais favorável. }\end{array}$ & $9 \%$ \\
D Solicitou o abono por causa do aspecto financeiro, pois com ele o salário não iria & $18 \%$ \\
E Niminuir e esse bônus na remuneração iria ajudar financeiramente. & $16 \%$ \\
F Informam que gostam muito do trabalho que realizam na universidade. & $31 \%$ \\
G Informaram outros motivos. & $6 \%$ \\
\hline
\end{tabular}

Fonte: dados da pesquisa

Conforme apresentado, pouco mais de um terço dos participantes da pesquisa apontou como principal causa para solicitar o Abono de Permanência o fato de gostar muito do trabalho desenvolvido na universidade. Isto vem confirmar os achados dos estudos de Carraher, Hart e Carraher (2003) quando identificaram que muitos funcionários trabalham melhor quando trabalham no que se identificam. Isto revela também que os servidores pesquisados sentem realização no trabalho realizado na universidade e inspiram um ambiente de comprometimento.

Mas não se pode deixar de salientar que o aspecto financeiro foi apresentado como motivo relevante para solicitar o Abono de Permanência, pois o adicional pecuniário proporcionado produz um impacto positivo na renda mensal do servidor. Isto corrobora com Lawler III (2000) quando defende a importância da remuneração para a permanência no emprego. E, um terceiro motivo mais apresentado pelos servidores foi o fato de se considerarem jovens e não se sentirem preparados para a aposentadoria, o que efetivamente foi constatado pela faixa etária dos mesmos. Talvez isto contribua para que os servidores não queiram se aposentar por medo do tédio, da solidão e da redução financeira que podem ser consequência da aposentadoria, como Fernandes, Marra e Lara (2016) e Marra et al. (2015) identificaram em seus estudos. 
Quanto a análise sobre o ambiente de trabalho na universidade, a maioria dos servidores caracterizou-o como bom e muito bom, em termos de estrutura física, equipamentos, mobiliário, comprometimento da equipe e gestão da chefia imediata. Porém, quase um terço deles reclamou da estrutura física, dos equipamentos e mobiliários, classificando-os como regular. Isto está relacionado aos ambientes diferenciados que existem na universidade e como os respondentes são membros de variadas as unidades acadêmicas, não há uma mesma condição de trabalho para todos.

Tabela 5 Caracterização do ambiente de trabalho

\begin{tabular}{lcccc}
\hline & Muito Boa & Boa & Regular & Ruim \\
\hline Estrutura física & $13 \%$ & $41 \%$ & $34 \%$ & $12 \%$ \\
Equipamentos e mobiliário & $12 \%$ & $49 \%$ & $30 \%$ & $9 \%$ \\
Comprometimento da equipe & $38 \%$ & $46 \%$ & $15 \%$ & $1 \%$ \\
Gestão da chefia & $43 \%$ & $42 \%$ & $14 \%$ & $1 \%$ \\
\hline
\end{tabular}

Fonte: dados da pesquisa

Com relação ao nível de exigência do trabalho realizado na universidade, a maioria dos servidores que está usufruindo do Abono de Permanência apontou como alto ou muito alto (Tabela 6). Isto sugere certo grau de preocupação quanto a este aspecto, uma vez que o nível de stress também foi salientado, embora foram identificadas variações do nível de stress, dependendo do trabalho que é realizado pelo servidor, uma vez que estão vinculados a unidades e funções distintas, como também identificaram Hansen (2005) e Vilela, Garcia e Vieira (2003).

Tabela 6 Caracterização do ambiente de trabalho

\begin{tabular}{lcccc}
\hline & Muito alto & Alto & Médio & Baixo \\
\hline Nível de exigência & $22 \%$ & $46 \%$ & $31 \%$ & $1 \%$ \\
Nível de estresse & $20 \%$ & $26 \%$ & $39 \%$ & $15 \%$ \\
\hline
\end{tabular}

Fonte: dados da pesquisa

Quando questionados sobre o nível de bem-estar no ambiente de trabalho, as respostas foram muito positivas. A maciça maioria respondeu que se sente satisfeito com as atividades que desempenha, sente-se bem com a equipe de trabalho e que seu trabalho contribui para seu progresso pessoal e profissional. Também destacaram que ainda pretendem participar de capacitações, o que sugere que esses servidores estão encarando esse período como uma continuidade efetiva da sua carreira na universidade. Destaca-se ainda que mais da metade 
dos servidores informaram não possuir problemas de saúde, corroborando com a idade deles que os permite muitos anos de trabalho pela frente.

Tabela 7 Nível de bem-estar no ambiente de trabalho

\begin{tabular}{lcc}
\hline \multicolumn{1}{c}{ Perguntas } & Sim & Não \\
\hline 1) Sente-se satisfeito com as atividades que desempenha & $94 \%$ & $6 \%$ \\
2) Sente que seu trabalho é reconhecido & $77 \%$ & $23 \%$ \\
3) Sente-se bem trabalhando com a equipe & $95 \%$ & $5 \%$ \\
4) O seu trabalho contribui para o progresso pessoal e intelectual & $90 \%$ & $10 \%$ \\
5) Possui algum problema de saúde & $32 \%$ & $68 \%$ \\
6) Sem o Abono de Permanência continuaria trabalhando & $67 \%$ & $33 \%$ \\
7) Participará de capacitações enquanto estiver no abono de permanência & $90 \%$ & $10 \%$ \\
\hline
\end{tabular}

Fonte: dados da pesquisa

Foi questionado também quanto tempo o servidor pretendia continuar no Abono de Permanência, ou seja, continuar trabalhando na universidade mesmo podendo se aposentar e grande parte respondeu que ainda não definiu por quanto tempo pretende ficar trabalhando na universidade ou só sairá quando chegar a aposentadoria compulsória. Isto pode sugerir o envolvimento desses servidores em continuar efetivamente trabalhando por até 15 anos, uma vez que $66,67 \%$ dos servidores que estão no abono e participaram da pesquisa têm de 51 a 60 anos. Babcock (2005) e Dejours (2004) também argumentam a importância subjetiva do trabalho para a vida das pessoas e isto pode ser identificado nas respostas dos pesquisados.

Tabela 8 Pretensão do servidor em permanecer trabalhando na UFPE

\begin{tabular}{llc}
\hline \multicolumn{1}{c}{ Respostas } & Percentual \\
\hline A & Até um ano & $15 \%$ \\
B & De 2 a 3 anos & $20 \%$ \\
C & Mais de 3 anos & $11 \%$ \\
D & Até completar a aposentadoria compulsória & $6 \%$ \\
E & Até quando sentir vontade & $4 \%$ \\
F & Ainda não sei, não pensei & $43 \%$ \\
G & Informaram outro motivo & $1 \%$ \\
\hline
\end{tabular}

Fonte: dados da pesquisa

\section{CONSIDERAÇÕES FINAIS}

O objetivo do presente estudo foi identificar os motivos que levam os servidores aposentáveis de uma universidade federal brasileira a solicitarem o Abono de Permanência e 
continuarem trabalhando, mesmo já tendo adquirido todas as condições para a aposentadoria voluntária.

Foi constatado que $15 \%$ do total de servidores ativos estão recebendo o Abono de Permanência na universidade e mais da metade tem entre 51 e 60 anos. Isto sugere que ainda têm muitos anos pela frente com a possibilidade de estarem trabalhando, uma vez que a aposentadoria compulsória no serviço público federal brasileiro exige 75 anos.

Os resultados indicam que grande parte dos servidores que participou da pesquisa solicitou o abono de permanência por gostar do trabalho que realiza, confirmando estudos como os de Dejours (2008), Souza et al. (2013) e Boas e Morin (2016) que acreditam que o trabalho proporciona prazer, autorrealização, orgulho e é grande motivador pessoal e profissional.

De certo modo, os resultados da pesquisa mostram que os servidores que estão recebendo o Abono de Permanência o fazem não só visando acréscimo pecuniário provisório, mas porque apesar de já terem muitos anos de efetivo exercício na universidade, não estão se sentindo velhos, desmotivados ou cansados do trabalho que realizam. Pretendem continuar se capacitando e efetivamente contribuindo com o desenvolvimento da organização em que estão inseridos. Isto confirma o que Ferreira et al. (2015) salientam da importância das ações de treinamento e desenvolvimento na Gestão de Pessoas que provoca mudanças nos resultados e sustentabilidade organizacional.

Grande parte dos servidores pesquisados se sente satisfeito com as tarefas que desempenha, recebe reconhecimento no trabalho e deseja continuar se capacitando. Estão se sentindo bem nas atividades que realizam na universidade e confirmam achados de autores como Steger, Dik e Duffy (2012) e Kubo, Gouvêa e Mantovani (2013).

Este estudo abordou apenas as opiniões sobre o ponto de vista dos servidores que estão recebendo o abono de permanência na universidade federal estudada, o que representa uma limitação, por não ter ouvido chefias e colegas dos mesmos, quanto por exemplo ao seu desempenho no trabalho, além de se tratar de um estudo de caso. Assim, estudos semelhantes podem ser realizados, para melhor entendimento da temática estudada.

\section{REFERÊNCIAS}

ANTUNES, M. H. Entre "o mito do pijama" e o "projeto de ser feliz"... Dissertação (mestrado) - Universidade Federal de Santa Catarina, Programa de Pós-Graduação em Psicologia, Florianópolis, 2014. Disponível em: https://repositorio.ufsc. 
br/bitstream/handle/123456789/123210/326768.pdf? sequence=1 Acesso em: novembro de 2016.

ANTUNES, M. H.; SOARES, D. H.; MORÉ, C. L. O. O. Repercussões da Aposentadoria na Dinâmica Relacional Familiar na Perspectiva do Casal. Psico, Porto Alegre, v. 46, n. 4, pp. 432-441, 2015.

APPELBAUM, E. et al. Manufacturing Advantage: Why High-Performance.Work Systems PayOff. Ithaca: Cornell University Press, 2000.

ARMSTRONG, M. Armstrong's hand book of human resource management practice. 12. ed. London: Kogan Page, 2012.

ASIF, M.; SEARCY, C.A composite index for measuring performance in higher education institutions. International Journal of Quality \& Reliability Management, v. 31, n. 9, p. 983-1001, 2014.

BABCOCK, P. Find what workers want.HR Magazine, Alexandria, v. 50, n. 4, 2005.

BARBOSA, A. ; FERREIRA, P. Gerenciamento de Recursos Humanos: o dimensionamento de pessoal técnico-administrativo da Universidade Federal de Sergipe. IX Colóquio Internacional sobre Gestão Universitária na América do Sul, 2009.

BOAS, A. A. V.; MORIN, E. Sentido do Trabalho e Fatores de Qualidade de Vida no Trabalho: a Percepção de Professores Brasileiros e Canadenses. Revista Alcance, v. 23, n. 3, p. 272-292, 2016.

BOLANDER, G.; SNELL, S. Administração de recursos humanos. Tradução da $14^{\mathrm{a}}$ ed. norte americana. São Paulo: Cengage Learning, 2009.

BRASIL. Emenda Constitucional n⿳0 05, de 16 de dezembro de 1998.

Emenda Constitucional $\mathbf{n}^{\mathbf{0}}$ 41, de 19 de dezembro de 2003.

. Emenda Constitucional $\mathbf{n}^{\mathbf{0}} \mathbf{2 0}$, de 16 de dezembro de 1998.

.Emenda Constitucional $\mathbf{n}^{\mathbf{0}} \mathbf{0 5}$, de 15 de agosto de 1995.

. Lei $\mathbf{n}^{\mathbf{0}} \mathbf{. 8 . 1 1 2}$, de 11 de dezembro de 1990.

1988 .

Constituição da República Federativa do Brasil de 1988, de 05 de outubro de

CAMBOIM, V. S. C.et al. Aposentadoria, o desafio da segunda metade da vida: estudo de caso em uma agência bancária. Revista Gestão Organizacional. v. 4, n. 1, art. 3, 2011.

CARMO, P. S. A ideologia do trabalho. São Paulo: Moderna, 2001. 
CARRAHER, S. M.; HART, D. E.; CARRAHER JR., C. Attitudes towards benefits among entrepreneurial employees. Personnel Review, v. 32, n. 6, 2003.

CARVALHO, A. I. et al. Escolas de governo e gestão por competências: mesa-redonda de pesquisa-ação. Brasília: ENAP, 2009.

CHEN, S.-H.; WANG, H.-H.; YANG, K.- J. Establishment and application of performance measure indicators for universities. The TQM Journal, v. 21, n. 3, p. 220-235, 2009.

CHEN, S.-H.; YANG, C.-C., SHIAU, J.- Y. The application of balanced scorecard in the performance evaluation of higher education. The TQM Magazine, v. 18, n. 2, p.190-205, 2006.

CLERKIN, Richard M., COGGBURN, JerrellD. The dimensions of public service motivation and sector work preferences, Review of Public Personnel Administration, v. 32, n. 3, p. 209-235, 2012.

COSTA, A. B. Projetos de futuro na aposentadoria. Dissertação (Mestrado em Psicologia), Programa de Pós-Graduação em Psicologia, Universidade Federal de Santa Catarina. Florianópolis, 2009. Disponível em: https://repositorio.ufsc.br/bitstream/handle/123456789/928 Acesso em: novembro de 2016.

CRESWELL, J. W. Projeto de Pesquisa: Métodos Qualitativo, Quantitativo e Misto. 2.ed. Porto Alegre: Artmed, 2007.

DAVEL, E.; VERGARA, S. C. Gestão com Pessoas, Subjetividade e Objetividade nas Organizações. In: (Orgs.). Gestão com pessoas e subjetividade. 6 ed. São Paulo: Atlas, 2013, p. 4-27.

DEBETIR, E. Aposentadoria - Oportunidade de Realizar Projetos e/ou Momento de Crise? Revista de Carreiras e Pessoas. v. 1, n. 2, 2011.

DEJOURS, C. Subjetividade, trabalho e ação. Revista Produção Online, Florianópolis, v. 14, n. 3, p. 27-34, 2004.

DEMO, G.; FERNANDES, T.; FOGAÇA, N. A Influência dos Valores Organizacionais na Percepção de Políticas e Práticas de Gestão de Pessoas. REAd. Revista Eletrônica de Administração, v. 23, n. 1, p. 89-117, 2017.

ELIAS, G. T. Regime Jurídico do Abono de Permanência. Revista do TCE de Minas Gerais, v. 72, n. 3, p.78-89julho-setembro, 2009. Disponível em: http://revista.tce.mg.gov.br/Content/Upload.pdf. Acesso em:18/05/2016.

FERNANDES, P. C. M.; MARRA, A. V.; LARA, S. M. Metamorfoses identitárias na préaposentadoria de servidores públicos. Revista de Carreiras e Pessoas, v. 6, n. 1, p. 86-99, 2016.

FERRAZ, V. N.; ROCHA, C. R. Políticas de recursos humanos no setor público: o que esperam os servidores...? In: EnGPR, 3, Anais... João Pessoa: ANPAD, 2011. 
FERREIRA, L. G.; ZIVIANI, F.; OLIVEIRA, J. L. R.; MEDEIROS, M. L. Influência dos Incentivos à Qualificação dos Servidores Técnico-Administrativos da Universidade Federal de São João Del Rei. Teoria e Prática em Administração, v. 5, n. 1, p. 183-203, 2015.

GOMES, C. F. S.; ALVES, M. R. Uma abordagem comparativa dos planos de carreiras e cargos do magistério superior. Revista de Carreiras e Pessoas, v. 5, n. 2, p. 250-269, 2015.

GRESSLER, L. A. Introdução à pesquisa: projetos e relatórios. 2. ed, São Paulo: Loyola, 2004.

HANSEN, F. Currents in compensation and benefits. Compensation and Benefits Review, v. 37, n. 1, 2005.

HLANDCHANKO, M. Balanced Scorecard - a strategic management system of the higher education institution. International Journal of Educational Management, v. 29, n. 2, p. 167-176, 2015.

HORTA, P.; DEMO, G.; ROURE, P. Políticas de gestão de pessoas, confiança e bem-estar: estudo em uma multinacional. Revista de Administração Contemporânea, Rio de Janeiro, v. 16, n. 4, p. 566-585, jul./ago. 2012.

IBGE. Síntese de Indicadores Sociais, Instituto Brasileiro de Geografia e Estatística, 2012.

JACKSON FILHO, J. M.; PONCE, T. B. O Papel dos Agentes de Recursos Humanos na Implementação da Política de Atenção à Saúde e Segurança do Trabalho do Servidor Público Federal (PASS). Revista do Serviço Público, v. 68, n. 1, p. 131-156, 2017.

KUBO, S. H.; GOUVÊA, M. A.; MANTOVANI, D. M. N. Dimensões do significado do trabalho e suas relações. Revista Pretexto, v. 14, n. 3, p. 28-28, 2013.

LAWLER III, E. Pay strategy: new thinking for the new millennium. Compensation and Benefits Review, v. 32, n. 1, 2000.

LIMA, M.; SERRA, F. R.; MEYER JUNIOR, V.; FERREIRA, M. P. Modelando o BSC para as Universidades do Sistema ACAFE. Organizações em contexto, v. 5, n. 9, p. 46-68, Jan./Jun., 2009.

LIMA, J. O.; SILVA, A. B. O significado de "ser servidor público" à luz da aprendizagem transformadora. RACE: Revista de Administração, Contabilidade e Economia, v. 13, n. 1, p. 97-122, 2014.

MACHADO, C. N. C.; LUCAS, M. G. Aposentadoria: Como Professores Vivenciam este Momento?. Revista de Carreiras e Pessoas, v. 7, n. 2, p. 576-588, 2017.

MAGAlHÃES, E. A. D.; SILVEIRA, S. D. F. R.; ABRANTES, L. A.; FERREIRA, M. A. M.; WAKIM, V. R. Custo do ensino de graduação em instituições federais de ensino superior: o caso da Universidade Federal de Viçosa. RAP, v. 44, n. 3, p. 637-666, maio/jun. 2010. 
MAINARDES, E. W.; MIRANDA, C. S.; CORREIA, C. H. A Gestão Estratégica de Instituições de Ensino Superior: Um Estudo Multicaso. Contextus - Revista Contemporânea de Economia e Gestão, v. 9, n. 1, p. 19-32, jan./jun. 2011.

MARCONI, N. A gestão de recursos humanos no governo federal: diagnóstico e proposta. Digesto Econômico, n. 457, p. 80-98, Abr. 2010.

MARRA, A. V.; MELO, M. C. D. O. L. A Prática Social de Gerentes Universitários em uma Instituição Pública. RAC, v. 9, n. 3, p. 9-31, jul./set. 2005.

MARRA, A. V. ; PINHEIRO, A. S. ; VALADARES, K. M. ; FERNANDES, P. C. M. . HERO NOT DIE: Reconstruction of Identity Professional of Retired Executives. Business Management Review (BMR), v. 4, p. 514-526, 2015.

MARRAS, J.P. Administração de Recursos Humanos: do operacional ao estratégico. 13 ed, São Paulo: Saraiva, 2009.

MEYER JUNIOR, V.; PASCUCCI, L.; MANGOLIN, L. Gestão estratégica: um exame de práticas em universidades privadas. RAP, v. 46, n. 1, p. 49-70, jan./fev., 2012.

MILKOVICH, G. T.; BOUDREAU, J. W. Administração de Recursos Humanos. São Paulo: Atlas, 2010.

MITCHELL; J. J.; RYDER, A. J. Developing and Using Dashboard Indicators in Student Affairs Assessment. New Directions for Student Services, v. 2013, n. 142, p. 71-81, 2013.

MOREIRA, J. O. Imaginários sobre aposentadoria, trabalho, velhice: estudo de caso com professores universitários. Psicologia em Estudo. vol.16. n. 4. Maringá, 2011. Disponível em: http://www.scielo.br/scielo.php?script=sci arttext\&pid=S141373722011000400005 Acesso em: junho de 2016.

MORRIS, S.; SNELL, S. The Evolution of HR Strategy: Adaptations to Increasing Global Complexity. In: WILKINSON, A. et al. (Eds.). The SAGE hand book of human resource management. London: Sage, 2010. p. 84-99.

MOURA, A. L. N.; DIAS, C. M.; SILVA JÚNIOR, A. S. Recursos Humanos sob a Luz do Modelo de Organização Multidimensional-Reflexivo: analisando a área de recursos humanos de uma instituição pública. In: EnANPAD, 37, Anais... Rio de Janeiro: ANPAD, 2013.

MOURA, A. L. N.; SOUZA, B. C. Gestão estratégica de pessoas na administração indireta do setor público federal... Revista do Serviço Público, v. 67, n. 4, p. 575-602, 2016.

NASCIMENTO, T. A.; SIMÕES, J. M. O sentido do trabalho no serviço público: reflexões a partir dos servidores da área de RH. In: EnGPR, Anais...João Pessoa: ANPAD, 2011.

NÉRI, A. L. Contribuições da psicologia ao estudo e à intervenção no campo da velhice. RBCEH - Revista Brasileira de Ciências do Envelhecimento Humano. Passo Fundo-RS, 
2004. Disponível em: http://www.upf.br/seer/index.php/rbceh/article/view/46/55 Acesso em: agosto de 2016

NGUYEN, Tho D., NGUYEN, Trang T. M. Firm-specific marketing capital and job satisfaction of marketers: evidence from Vietnam. The Learning Organization, v. 18, n. 3, p.251-263, 2011.

OLIVEIRA, J. M.; ESTIVALETE, V. F. B.; ANDRADE, T.; COSTA, V. F. Gestão de Pessoas e Sustentabilidade: Construindo Caminhos por Meio das Práticas de Capacitação. Revista de Administração da UFSM, v. 10, n. Ed. Especial, p. 108-126, 2017.

OLIVEIRA, P. W. S. de; LEONE, R. J. G. Gestão Estratégica de Benefícios: proposição de um modelo matemático para assistência médica de funcionários. Revista de Administração Mackenzie, v. 9, n. 2, p. 104-127, 2008.

PAIVA, R. C. V. D.; BARBOSA, F. V.; GONÇALVES, R. G.; COSTA, D. D. M. Educação Superior Privada: Um Estudo do Desempenho Financeiro em nove Instituições de Ensino Superior. Revista Gestão \& Tecnologia, v. 14, n. 1, p. 66- 97, jan./abr., 2014.

PALÁCIOS, F. A. C. Mudança Estratégica em uma Universidade Pública: Interferência da Interpretação dos Gestores no Processo. AOS - Amazônia, Organizações e Sustentabilidade, v. 3, n. 2, p. 83-99, jul./dez., 2014.

PINGLE, S.; NATASHAA, K..Performance management in institutes of higher education, through balanced scorecard. Ganpat University-Faculty of Management Studies Journal of Management and Research (GFJMR), v. 2, p. 1-20, 2011.

PIRES, A. K. et al. Gestão por competências em organizações de governo. Brasília: ENAP, 2005.

PIRES, J. S. D. B.; ROSA, P. M. D.; SILVA, A. T. D. Um Modelo de Alocação de Recursos Orçamentários Baseado em Desempenho Acadêmico para Universidades Públicas. ASAA Advances in Scientific and Applied Accounting, v. 3, n. 2, p. 239-270, 2010.

RODRIGUES, N. C. Aspectos sociais da aposentadoria. In Schons, C. R. \& Palma, L. S. (Orgs.), Passo Fundo-RS, 2000.

ROMANINI, D. P.; XAVIER, A. A. P.; KOVALESKI, J. L. Aposentadoria: período de transformações e preparação. Revista Gestão Industrial. V. 01, n. 03, 2005.

SALLES, D. M. R.; NOGUEIRA, M. G. Carreiras no Serviço Público Federal: Antigos Dogmas, Novas Perspectivas. In: COSTA, I.de S. A. e BALASSIANO, M (Orgs.). Gestão de carreiras: dilemas e perspectivas. São Paulo: Atlas, 2013. p. 134-149.

SANSEVERINO, A. M.; GOMES, C. F. S. Propostas dos Técnicos em Assuntos Educacionais. Revista de Carreiras e Pessoas, v. 7, n. 1, p. 476-494, 2017. 
SENA, A. S. de; GUARNIERI, P. Enterprise Resource Planning governamental: a percepção dos servidores atuantes no Projeto Ciclo do Ministério da Justiça quanto à implementação. Revista de Administração Pública, Rio de Janeiro, v. 49, n. 1, p. 207-230, jan./fev. 2015.

SERTÃo, A. S. L. Abono de Permanência. 25 de maio de 2005. Artigo. Disponível em: http://www.tce.pi.gov.br/documentos/artigos/abono permanencia .pdf. Acesso em: junho de 2016.

SILVA, J. R. da; BALASSIANO, M.; SILVA, A. R. L. da. Burocrata proteano: articulações de carreira em torno e além do setor público. Revista de Administração Contemporânea, Rio de Janeiro, v. 18, n. 1, p. 1-19, jan./fev. 2014.

SILVEIRA, V. N. S.; MIRANDA, D. L. A. Estratégias de Gestão de Pessoas e as Abordagens Normativas: Uma Análise Conceitual no Contexto da Gestão Estratégica de Pessoas. In: XXXV ENANPAD, 2011, Rio de Janeiro, Anais... RJ: ANPAD, 2011.

SPIRDUSO, W. W. Dimensões físicas do envelhecimento. São Paulo: Editora Manole, 2005.

SOARES, D. H. P. et al. Aposenta-Ação: programa de preparação para aposentadoria. Estudos Interdisciplinares sobre o Envelhecimento. Porto Alegre, 2007. Disponível em: http:// www.seer.ufrgs.br/index.php/RevEnvelhecer/article/view/4984/2853 Acesso em: maio de 2016.

SOUZA, M. M. P.; MARQUES, A. L.; MELO, M. C. O. L.; MARRA, A. V. Significado do trabalho e envelhecimento. Revista Adm em Diálogo, v. 15, n. 2, p. 103-128, 2013.

STEFANO, S. R; CAMPOS, E. A. R. de; CHRIST, E. Práticas de benefícios sociais nas organizações: desafios na gestão de pessoas. Revista Cesumar Ciências Humanas e Sociais Aplicadas, v. 19, n. 1, p. 65-68, jan-jun, 2014.

STEGER, M. F.; DIK, B. J.; DUFFY, R. D. Measuring Meaningful Work: The Work and Meaning Inventory (WAMI). Journal of Career Assessment, v. 20, n. 3, p. 322-337, 19 fev 2012.

SURYADI, K..Framework of Measuring Key Performance Indicators for Decision Support in Higher Education Institution. Journal of Applied Sciences Research, v. 3, n. 12, p. 16891695, 2007.

TACHIZAWA, T; FERREIRA, V. C. P.; FORTUNA, A. A. M. Gestão de Pessoas: uma abordagem aplicada às estratégias de negócios. $3^{\mathrm{a}}$ ed. Rio de Janeiro: FGV, 2004.

TANURE, B.; EVANS, P.; CANÇADO, V. L. As quatro faces de RH...RAC, Curitiba, v. 14, n. 4, p. 594-614, jul./ago. 2010.

TARDIF, M.; RAYMOND, D. Saberes, tempo e aprendizagem do trabalho no magistério.

Educação e Sociedade. v. 21, n. 73. Campinas, 2000. Disponível em:

http://www.scielo.br/pdf/ es/v21n73/4214.pdf Acesso em: junho de 2016. 
UMASHANKAR, V.; DUTTA, K. D. Balanced scorecards in managing higher education institutions: an Indian perspective. International Journal of Educational Management, v. 21, n. 1, p. 54-67, 2007.

VERGARA, S. C. Métodos de pesquisa em administração. São Paulo: Atlas, 2005.

VILELA, E. F.; GARCIA, F. C.; VIEIRA, A. Vivências de prazer-sofrimento no trabalho do professor universitário: estudo de caso em uma instituição pública. Revista Eletrônica de Administração, v. 19, n. 2, p. 517-540, 2013.

WANG, M.; HENKENS, K.; SOLINGE, H. V.; Retirement Adjustment: A Review of Theoretical and Empirical Advancements. American Psychologist, Vol. 66, No. 3, April, 2011, p.. 204-213.

WOOD JR., T.; TONELLI, M. J.; COOKE, B. Colonização e neo-colonização da gestão de recursos humanos no Brasil (1950-2010). Revista de Administração de Empresas, São Paulo, v. 51, n. 3, p. 232-243, 2011.

ZANELLI, J. C.; SILVA, N.; SOARES, D. H. P. Orientação para aposentadoria nas organizações de trabalho: construção de projetos para o pós-carreira. Porto Alegre: Artmed, 2010 . 